\title{
The Integral Assessment of Sustainable Development of the Enterprise
}

\author{
Diana Sergeevna Kandaurova ${ }^{1}$
}

Svetlana Igorevna Ashmarina1

G.R. Khasaev ${ }^{1}$

Anna Sergeevna Zotova1

\author{
${ }^{1}$ Samara State University of Economics, Russia, 443090, Samara, Sovetskoi Armii Street, 141 \\ Correspondence: Anna S. Zotova, Samara State University of Economics, Russia, 443090, Samara \\ Sovetskoi Armii Street, 141, Email: azotova@mail.ru
}

\section{Doi:10.5901/mjss.2015.v6n6s3p522}

\section{Abstract}

\begin{abstract}
The priority of Russian enterprises development has been given to the optimization process of industrial enterprise activity for their sustainable development in long-term period. The assessment of sustainable development level as one of the most efficient instruments of sustainable development management at the industrial enterprise gives complex view of its state. In order to perform accurate analysis of the current state of industrial enterprise it is necessary to perform the assessment of its sustainable development and using its results to elaborate the further tactic of enterprise functioning. The assessment of sustainable development level of the enterprise may help the effective management of strategy development only if the corresponding indicators system is created. The elaboration and usage the sustainable development indicators allows the enterprise to implement analysis of its activity results and monitoring of sustainable enterprise functioning. The authors' methods are based on general aspects of industrial enterprise functioning such as finance, customers, inner economic process, staff system.
\end{abstract}

Keywords: sustainable development, assessment methods, indicators system, industrial enterprise.

\section{Introduction}

The main task which determines the enterprise movement to the defined aim is its social and economic development. The direction for movement is defined by the enterprise itself which takes the chosen strategy as the main guideline for it. So the aim is one of the main driving force motivating the enterprise for progressive development.

The assessment of economic system functioning efficiency is necessary to be performed on the basis of significant and sufficient indicators. The indicators reflecting the key moments of functioning are used to characterize the most significant aspects of enterprise activity and the achievement degree of the main aim.

International and Russian economics practice has the innumerous number of various approaches to the determination of necessary quantity and quality of assessment indicators. (Porter, 2004; Dyllick, 2002)

The most progressive enterprises started to use the system of interconnected indicators in order to compose the financial and economic accounts in 20ies of the previous century. The most well-known example of such system is the DuPont model (Groppelli, 2000). At that time the system of accounting indicators had clear correlation between the tasks of the enterprise and the indicators characterizing these tasks. Most of the modern key indicators systems are based on the purpose-oriented approach. The difference lies only in the ways which the enterprise uses to achieve the set aims.

It is necessary to elaborate some mechanism allowing following the consequences of changes and the results of the enterprise activity in order to implement strategy management at the enterprise. Such mechanism was offered by the KPI models which started their rapid development in 1980 - $1990 \mathrm{~s}$. The development was stipulated by the competitiveness growth, new technologies development, the growth of social responsibility of the enterprise, the development of international cooperation and globalization processes.

The most elaborated and wide- spread of them are the model of «Balanced Scorecard» (Norton, Kaplan, 2001) ; « Performance Pyramid » (Lynch, 1991) и « Tableau de Bord » (Epstein, 1997 ; Lebas, 1996).

The activity targeted at the determination of sustainable development level of the enterprise may help the effective 
management of strategy development only if the corresponding indicators system is created. The elaboration and usage the sustainable development indicators allows the enterprise to implement analysis of its activity results and monitoring of sustainable enterprise functioning.

The authors' methodical instruments are based on general aspects of industrial enterprise functioning such as finance, customers, inner economic process, staff system. Each component includes indicators reflecting the most significant parameters of sustainable development such as economy constituent, social constituent, ecology constituent and foreign-economic activity.

\section{Methodological Framework}

It is important to take into account some demands that the indicators system should meet:

- the indicators should be formulated clearly and have such characteristics as directness, applicability, practicality; they should determine the interests of various economic entities; they should be understandable and reproducible;

- the indicators should provide with ability to express all correlation and interconnection with quantitative forms;

- the number of assessment indicators should be minimized but their number should be sufficient for overall and qualitative reflection of all factors that influence the level of sustainable development ;

- -the accounting of the indicators should be based on the current information, be objective and free of subjective opinion of the analytics;

- the indicators should be simple for calculation, should have physical sense and should be defined accurately enough without loss of time;

- the indicators should meet the principles of enterprise sustainable development.

\section{Results}

\subsection{Elaboration of the indicators system for sustainable development assessment.}

The system of assessing indicators was formed so two stages of analysis were realized, further it is necessary to elaborate the methodical instruments for assessment. The system of assessment indicators is presented in Figure 1.

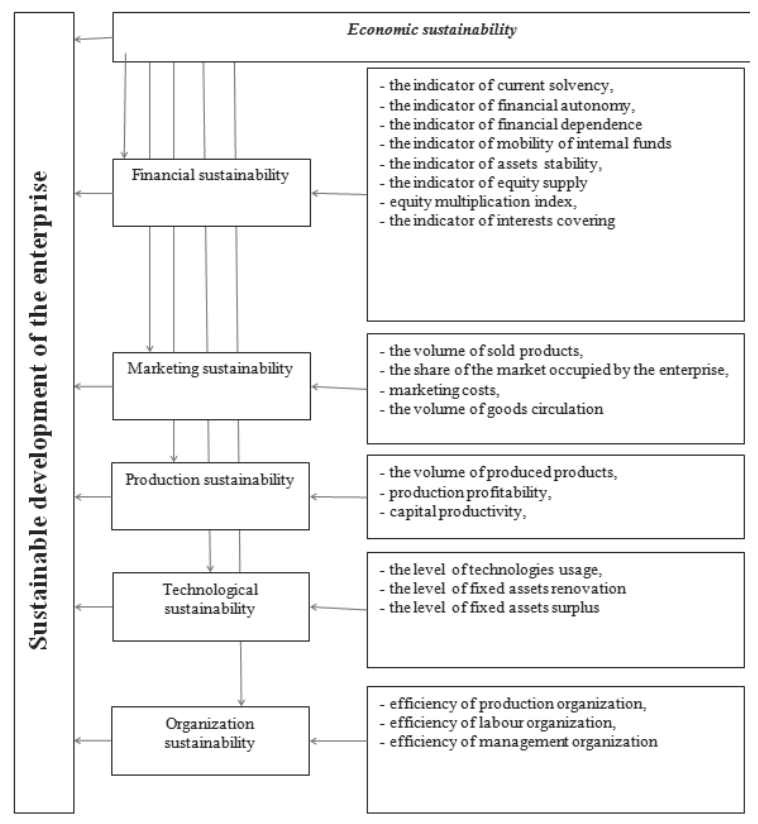



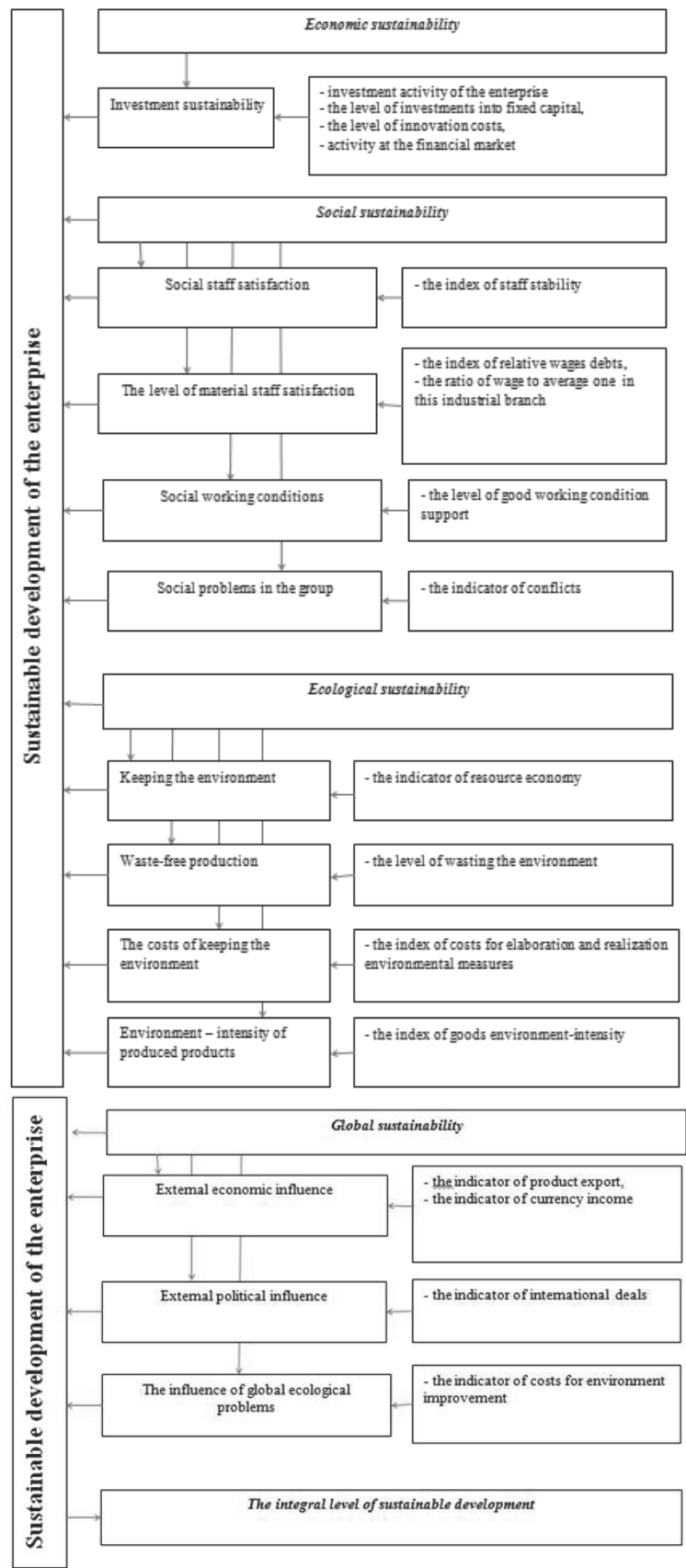

The suggested system includes four main groups of indicators: economic sustainability, social sustainability, ecological sustainability and global sustainability. Economic sustainability defines the ability of industrial enterprise to develop effectively and efficiently under the condition of constant transformations in the external business environment. Social sustainability shows the general qualification and creative characteristics of staff, defines the ability of the personnel to implement the set tasks in order to raise the enterprise efficiency. Ecological sustainability determines the correlation 
between the enterprise economy and its ecological safety. It shows how complex is the investment decision, whether it takes into account both economic and ecological questions. Global sustainability defines the dependence of the enterprise on the global factors that may influence its sustainable development. The determination of global sustainability is becoming especially important now when the global processes both in the economy and politics influence the enterprise functioning.

The quantitative results of the analyzed indexes are defined according to the formulas. Then the experts should set the weigh indicators of the elements of the assessment system giving the percent of their importance and significance in the whole assessment system.

The sum of calculated separate indicators at each element of the assessing system (economic, social, ecological and global sustainability) multiplied with its weigh indicator characterizes the integral index of the element.

\subsection{The integral level of sustainable development was defined.}

In order to define the integral level of sustainable development we compose the circle diagram whose coordinate axes show the calculated indexes of integral assessment of each sustainable development element (economic, social, ecological and global sustainability). The integral level can be defined by the area of the created figure.

So the integral level of sustainable development can be defined. It can be the basis for further conclusion about the enterprise possibility to implement its development strategy (Figure 2).

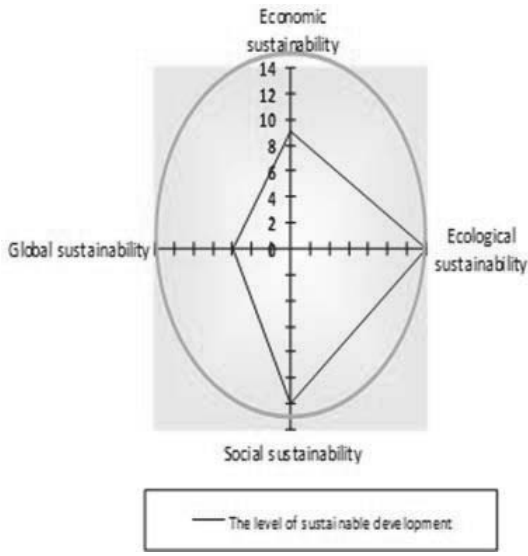

Figure 2. The level of sustainable development of the enterprise

\section{Discussions}

The elaborated authors' methodical instrument is unified for all industrial enterprises, because it meets the main principles of system analysis, it is rather complex and uses corresponding figures of indicators, it is also based on truthful and nonexclusive information. As a result of the performed research work it turned out that there is some necessity to elaborate the practical activity and events targeted at increasing the level of sustainable development which is based on some certain mechanism.

\section{Conclusion}

The suggested approach to the sustainable development assessment is implemented in several stages the basic of which are the definition of aims and tasks of analysis, the elaboration of assessing indicators system, implementing the calculations, forming the conclusion according the data get as the result of the analysis.

The next stage is the analysis of integral level of sustainable development which is implemented on the basis of the study of the main directions of sustainable development such as economic sustainability, ecological sustainability, social sustainability, global sustainability. Each of them has its own system of assessment indicators. 
The suggested methodical approach significantly differs from the traditional methods of sustainable development assessment where there is no possibility of both qualitative and quantitative research for more complex study and no possibility for determination the reserves for efficiency growth of the enterprise sustainable development.

\section{Acknowledgments}

The authors thank all participants of the study for their kind cooperation.

\section{References}

Dyllick, T. \& Hockerts, K.( 2002) Beyond the business case for corporate sustainability. Business Strategy and the Environment, 11(2): $130-141$.

Epstein, M. J. \& Manzoni, J. F. (1997). The Balanced Scorecard and Tableau De Board: A Global Perspective on Translating Strategy into Action, in Management Accounting (August). Pp. 28-36.

Groppelli, Angelico A.; Ehsan Nikbakht (2000). Finance, 4th ed. Barron's Educational Series, Inc. pp. 444-445. ISBN 0-7641-1275-9.

Kaplan R.S., Norton D.P., (2001)The strategy-focused organization: how balanced scorecard companies thrive in the new business environment. - Boston: Harvard Business School Press.

Lebas M. (1996), "Management accounting practice in France", dans Bhimani A., Management Accounting: European Perspectives, Oxford University Press, p.74-99.

Lynch, R. L. \& Cross, K. F. (1991). Measure Up! Yardsticks for Continuous Improvement, Basilblackwell, Oxford.

Porter M.E., (2004) Competitive advantage: creating and sustaining superior performance. New York: Free Press. 